Article

\title{
Perilla frutescens Britton: A Comprehensive Study on Flavor/Taste and Chemical Properties During the Roasting Process
}

\author{
Jookyeong Lee ${ }^{1,+}$, Da-Som Kim ${ }^{1,+}$, Jinju Cho ${ }^{1}$, Seong Jun Hong ${ }^{1}$, Jeong Hoon Pan ${ }^{2}$, \\ Jae Kyeom Kim ${ }^{2}$ and Eui-Cheol Shin $1, *$ D \\ 1 Department of Food Science, Gyeongnam National University of Science and Technology, Jinju 52725, Korea; \\ tracylee0911@gmail.com (J.L.); kim94dasom@naver.com (D.-S.K.); aacho7@hanmail.net (J.C.); \\ 01028287383a@gmail.com (S.J.H.) \\ 2 School of Human Environmental Sciences, University of Arkansas, Fayetteville, AR 72701, USA; \\ jhpan@uark.edu (J.H.P.); jkk003@uark.edu (J.K.K.) \\ * Correspondence: eshin@gntech.ac.kr; Tel.: +82-55-751-3271; Fax: +82-55-751-3279 \\ + These authors contributed equally to this work.
}

Academic Editor: Henryk H. Jeleń

Received: 4 March 2019; Accepted: 8 April 2019; Published: 8 April 2019

\begin{abstract}
This study investigated changes of volatile compounds, sniffing test-assisted sensory properties, taste associated-constituent and free amino acid compositions, taste description by electronic-tongue, and chemical characteristics in Perilla frutescens Britton var. acuta Kudo after roasting at $150{ }^{\circ} \mathrm{C}$ for $0-8 \mathrm{~min}$. A total of 142 volatile compounds were identified, among which methyl benzoate and limonene were predominant, regardless of roasting time, and these were also detected as the major compounds in the sniffing test by GC-olfactometry. For constituent amino acids analyzed by the acid hydrolysis method using hydrochloric acid $(\mathrm{HCl})$, the concentration of glutamic acid, aspartic acid, and leucine showed an increase pattern with increased roasting time, which results in umami taste, sour taste, and bitter taste, respectively. For free amino acids, valine and hydroxylysine eliciting bitter and bitter and sweet tastes, respectively, also tend to increase by roasting. The pattern of amino acid concentration by roasting was readily matched to the taste description by electronic-tongue but that of sweetness and sourness by electronic-tongue did not coincide with the amino acid composition. For the chemical properties, total phenolic content, antioxidative capacity, and browning intensity tend to increase with roasting but decreased by $8 \mathrm{~min}$. The results of this study provide fundamental information on perilla in both the food industry and cooking environment for the sake of increasing the utilization of perilla as a food source and ingredient.
\end{abstract}

Keywords: Perilla frutescens Britton; roasting; taste; electronic-tongue; flavor; sniffing test; GC-olfactometry; chemical properties

\section{Introduction}

Perilla frutescens is an herbaceous plant that belongs to the Lamiaceae family and grown in Asian countries including Korea, China, Japan, Vietnam, and India [1,2]. It was first cultivated and established as a traditional medicinal plant in China a long time ago [1,3]. Perilla frutescens was introduced to Korea in ancient times and has been widely cultivated as a major crop since then [4]. There are various cultivars: P. frutescens var. frutescens is consumed as an oil source and fresh vegetable, $P$. frutescens var. japonica as an oilseed, and $P$. frutescens var. acuta and $P$. frutescens var. crispa mainly as fresh vegetables, food ingredients, and medicinal herbs [1-3,5]. P. frutescens var. acuta and P. frutescens var. crispa, are differentiated by the anthocyanin content accumulated in their leaves, whereby they display red-purple and green-purple leaves, and thereby being called red perilla and green perilla, respectively [5]. 
The literature highlights various biological effects of Perilla frutescens. Jun et al., investigated phenolic antioxidant capacity of $P$. frutescens var. acuta leaves [6] and Zhou et al., reported that two phenolic compounds in cold-pressed $P$. frutescens var. arguta seed flour, namely rosmarinic acid and rosmarinic acid-3-O-glucoside, had superior antioxidant activities [7]. In addition to the antioxidative capacity, Jeon et al., identified luteolin in perilla leaves using HPLC and found that luteolin had anti-inflammatory activity against cytokines and antipruritic activity in mice [8]. Further, Kim et al., evaluated the antibacterial activity against Staphylococcus aureus of P. frutescens var. acuta leaves [9]. Kim et al., discovered that pepsin-hydrolyzed perilla leaf extracts had anti-neuronal damage activity on $\mathrm{H}_{2} \mathrm{O}_{2}$-induced DNA [10]. Lastly, He et al., isolated seven anthocyanins in P. frutescens var. acuta and reported anticancer activity against Hela cells [1].

Whereas much research has focused on the physiological and biological benefits of perilla as aforementioned [1,6-10], only a few studies have examined the changes of flavor and taste characteristics and chemical properties after a cooking process such as roasting. Two different studies applied response surface methodology (RSM) to optimize the roasting conditions of perilla leaves as a tea and found that roasting each at $210-220^{\circ} \mathrm{C}$ for $10-20 \mathrm{~min}$ and $180^{\circ} \mathrm{C}$ for $20 \mathrm{~min}$ yielded the best quality perilla leaf tea $[10,11]$. These studies focused on the optimization of roasting conditions but did not examine the alterations of the taste and flavor and of chemical properties over the roasting time. Further, Nam et al., tried to optimize steaming time and onion contents to make perilla pickles [12], and Moon et al., added perilla leaf powder to pork sausages in an investigation of its impact on sausage quality and consumer preference [13]. These two studies introduced perilla as a food ingredient and food additive but, again, did not analyze volatile compounds and the most relevant chemical parameters from a food chemistry perspective.

Therefore, this study aimed to investigate comprehensive changes in $P$. frutescens Britton var. acuta Kudo during roasting at $150^{\circ} \mathrm{C}$ for various time points $\left.(0-8 \mathrm{~min}) ; 1\right)$ volatile compounds and sniffing test assisted sensory properties to examine flavor changes upon roasting; 2 ) taste related-constituent and free amino acid compositions and taste description by electronic tongue (E-tongue) to access taste changes by roasting; and 3) total phenolic content (TPC), antioxidative capacity, and browning intensity to describe chemical changes by roasting, in an effort to widen the application of perilla as food ingredients. The results of this study would provide informative data in food industrial applications and serve as a cornerstone in recognizing the potential of perilla as great food sources and food ingredients.

\section{Results and Discussion}

\subsection{Votile Compounds and Sensory Desciption by GC-Olfactometry}

\subsubsection{Volatile Compounds Analyzed by GC-MS}

Volatile compounds present in P. frutescens Britton during the roasting process were collected with SPME and analyzed by GC-MS. The results of changes in the volatile compounds are shown in Table 1. A total of 142 volatile compounds were found in P. frutescens Britton var. acuta Kudo, among which hydrocarbons (110) accounted for the majority, followed by alcohols (16), miscellaneous compounds (5), aldehydes (5), heterocyclic compounds (3), ethers (2), and ketones (1). Of those volatile compounds, methyl benzoate and limonene were identified as predominant compounds in terms of relative concentration. Methyl benzoate was initially present in high concentration $(88.08 \mu \mathrm{g} / 100 \mathrm{~g})$ and then it increased to $203.10 \mu \mathrm{g} / 100 \mathrm{~g}$ at $4 \mathrm{~min}$. It finally showed a substantial decrease after $8 \mathrm{~min}$ of roasting $(21.31 \mu \mathrm{g} / 100 \mathrm{~g})$. Methyl benzoate is an aromatic ester compound eliciting pleasant odors associated with herbal and fruity odors [14,15]. Recent studies demonstrated that methyl benzoate was identified as a major volatile compound in fermented green oranges [15], olives [16], and teas [17]. Similarly, limonene started with a relatively high concentration $(54.66 \mu \mathrm{g} / 100 \mathrm{~g})$, which increased to $137.24 \mu \mathrm{g} / 100 \mathrm{~g}$ at $4 \mathrm{~min}$, and then decreased to $60.92 \mu \mathrm{g} / 100 \mathrm{~g}$ at $8 \mathrm{~min}$. Limonene is an aliphatic terpene usually derived from oils in the peels of citrus fruits invoking citrus-like fruity odors [18]. 
Researchers described that limonene was one of the key volatile compounds in encapsulated orange oil [19], Chinese wolfberry [20], and Persian lime [21]. In this study, although 8-min roasting seems long enough to decompose both methyl benzoate and limonene, they remained at relatively high contents during the roasting process as they are known to be thermally stable compounds with high boiling points (198 ${ }^{\circ} \mathrm{C}$ [22] and $175-177^{\circ} \mathrm{C}$ [22], respectively). Besides those main compounds, there were low quantities of linalool, $\alpha$-pinene, $2-\beta$-pinene, azulene, dodecane, tetradecane, and caryophyllene which showed varying patterns over time. Dodecane and tetradecane showed good heat resistance, maintaining similar contents during the roasting, with a range of 1.79-2.44 $\mu \mathrm{g} / 100 \mathrm{~g}$ and $1.84-3.15 \mu \mathrm{g} / 100 \mathrm{~g}$, respectively. All of these volatiles showed the highest concentration at $4 \mathrm{~min}$ except for dodecane, which had the highest at $6 \mathrm{~min}$. Ahmed et al., reported that perilla aldehydes, perilla ketones, limonene, shisofurane, and farnesene were the core compounds among 65 volatile compounds identified in the essential oil of P. frutescens (L). Britt [23]. Another study by Seo and Baek found 33 volatile compounds using GC-MS in the leaf of $P$. frutescens Britton with four different extraction methods and identified perilla ketone, (Z)-3-hexenol, and 1-octen-3-ol as key compounds [24]. The results of the mentioned studies were slightly discrepant with what we observed in this study, presumably because of the differences in varieties (e.g., Britt vs. Britton) and sample preparation (e.g., heat treatment vs. four different extractions). One of the key mechanisms in developing volatile compounds is Maillard reaction, known as a non-enzymatic reaction [25]. Approximately 3500 volatile compounds are generated through Maillard reactions in the presence of amino acids, reducing sugars, and heat [25]. This additional heat largely governs the reaction by affecting the rate of volatile compound generation [25]. In general, low molecular weight decomposition products of amino acids and carbohydrates such as aldehydes and ketons are generated through Maillard reactions [25]. Based on the result of this study, 4 min roasting at $150{ }^{\circ} \mathrm{C}$ would be the optimum condition to retain the high amounts of volatile compounds in P. frutescens Britton.

Table 1. Changes in volatile compounds in P. frutescens Britton var. acuta Kudo during the roasting.

\begin{tabular}{|c|c|c|c|c|c|c|c|}
\hline \multirow{3}{*}{ Compounds ${ }^{1)}$} & \multirow{3}{*}{$\begin{array}{l}\text { Retention Time } \\
\text { (min) }\end{array}$} & \multirow{3}{*}{$\begin{array}{l}\text { Retention } \\
\text { Index }\end{array}$} & \multicolumn{5}{|c|}{ Roasting Time (min) } \\
\hline & & & 0 & 2 & 4 & 6 & 8 \\
\hline & & & \multicolumn{5}{|c|}{ Relative Concentration ( $\mu \mathrm{g} / \mathbf{1 0 0} \mathrm{g})$} \\
\hline \multicolumn{8}{|l|}{ Alcohols (16) } \\
\hline Isooctanol & 17.71 & 1088 & 0.07 & $\mathrm{ND}^{2)}$ & ND & ND & ND \\
\hline 3,7-Dimethyl-1,6-octadien-3-ol & 18.29 & 1102 & ND & 2.70 & ND & ND & ND \\
\hline Linalool & 18.31 & 1103 & 1.64 & ND & 4.15 & 3.52 & 0.50 \\
\hline 2-Ethyl-1-decanol & 18.41 & 1107 & 0.46 & ND & ND & ND & ND \\
\hline 3,4-Dimethyl cyclohexanol & 18.62 & 1114 & ND & 0.36 & ND & ND & ND \\
\hline 3,5-Dimethyl cyclohexanol & 18.64 & 1115 & 0.29 & ND & 0.31 & ND & 0.26 \\
\hline 2-Ethyl-1-dodecanol & 18.73 & 1118 & 0.20 & ND & ND & ND & ND \\
\hline 3,7,11-Trimethyl-1-dodecanol & 18.83 & 1122 & 0.13 & ND & ND & ND & ND \\
\hline 8-Methylene-2-exo-noradamantanol & 21.81 & 1226 & ND & ND & 1.35 & ND & ND \\
\hline 2-Methylene cycloheptanol & 22.25 & 1242 & ND & ND & ND & 0.30 & ND \\
\hline 1-Tridecanol & 22.32 & 1245 & ND & ND & ND & ND & 0.12 \\
\hline 4-1-Methyl ethenyl-1-cyclohexene-1-methanol & 24.02 & 1306 & ND & 1.48 & ND & ND & ND \\
\hline Perilla alcohol & 24.02 & 1306 & ND & ND & 1.93 & ND & ND \\
\hline 1-Eicosanol & 27.62 & 1464 & ND & 0.66 & ND & ND & ND \\
\hline Isopulegol & 28.34 & 1501 & ND & ND & ND & 0.22 & ND \\
\hline 1-Ethynyl-2-methyl cyclohexanol & 29.35 & 1544 & 0.34 & ND & ND & ND & ND \\
\hline \multicolumn{8}{|l|}{ Aldehydes (5) } \\
\hline 6-Oxononanal & 18.64 & 1232 & ND & ND & ND & 0.30 & ND \\
\hline 2-Undecenal & 21.98 & 1115 & 0.31 & ND & ND & ND & ND \\
\hline Citral & 23.19 & 1277 & ND & ND & 0.17 & 0.36 & ND \\
\hline 2-Eehoxybenzaldehyde & 23.60 & 1291 & ND & ND & ND & ND & 0.48 \\
\hline Caryophyll-5-en-12-al & 30.58 & 1596 & ND & 0.65 & ND & ND & ND \\
\hline \multicolumn{8}{|l|}{ Esters (2) } \\
\hline Phosphonic acid, dioctadecyl ester & 26.20 & 1393 & ND & 0.28 & ND & 0.21 & ND \\
\hline 2-Ethyl hexyl ester & 29.00 & 1529 & 1.42 & 0.92 & ND & ND & 0.78 \\
\hline
\end{tabular}


Table 1. Cont.

\begin{tabular}{|c|c|c|c|c|c|c|c|}
\hline \multirow{3}{*}{ Compounds ${ }^{1)}$} & \multirow{3}{*}{$\begin{array}{l}\text { Retention Time } \\
\text { (min) }\end{array}$} & \multirow{3}{*}{$\begin{array}{l}\text { Retention } \\
\text { Index }\end{array}$} & \multicolumn{5}{|c|}{ Roasting Time (min) } \\
\hline & & & 0 & 2 & 4 & 6 & 8 \\
\hline & & & \multicolumn{5}{|c|}{ Relative Concentration $(\mu \mathrm{g} / 100 \mathrm{~g})$} \\
\hline Hydrocarbons (110) & & & & & & & \\
\hline 5-Methyl styrene-1,6-heptadien-3-yne & 11.74 & 921 & 0.13 & ND & ND & ND & ND \\
\hline 1,5-Cyclooctadiyne & 11.72 & 921 & ND & 0.24 & ND & ND & ND \\
\hline$\delta$-3-Carene & 12.87 & 956 & ND & ND & 0.10 & ND & 0.10 \\
\hline$\alpha$-Phellandrene & 12.87 & 956 & ND & ND & ND & 0.06 & ND \\
\hline 2,6,6-Trimethyl bicyclo hept-2-ene & 13.06 & 962 & ND & 3.26 & ND & ND & ND \\
\hline$\alpha$-Pinene & 13.08 & 963 & 2.65 & ND & 6.42 & 4.26 & 0.10 \\
\hline 3,7-Dimethyl-1,3,6-octatriene & 13.10 & 963 & ND & ND & ND & ND & 0.76 \\
\hline 6-Methylene bicyclo-3,2,0-heptane & 13.35 & 970 & ND & ND & ND & 0.13 & ND \\
\hline 4-Methyl bicyclo-3,2,1-octan-3-ene & 13.36 & 971 & ND & ND & 0.11 & ND & ND \\
\hline Sabinene & 14.38 & 998 & ND & ND & 2.05 & 0.62 & 0.56 \\
\hline 2 - $\beta$-Pinene & 14.50 & 1002 & 3.02 & 3.91 & 5.65 & 3.59 & ND \\
\hline$\beta$-Myrcene & 14.90 & 1014 & ND & 0.44 & 1.31 & 0.57 & ND \\
\hline Cyclofenchene & 14.93 & 1014 & 0.32 & ND & 0.85 & ND & ND \\
\hline 2,6,6-Trimethylbicyclo-3,1,1-hept-2-ene & 14.93 & 1014 & ND & ND & ND & ND & 0.17 \\
\hline$\alpha$-Fenchene & 15.35 & 1026 & ND & ND & ND & 0.54 & ND \\
\hline 6,6-Dimethyl-2-methylene bicyclo-3,1,1-heptane & 15.35 & 1026 & 0.45 & ND & ND & ND & ND \\
\hline 1-Methyl-5-1-methyl ethenyl cyclohexene & 15.36 & 1027 & ND & ND & ND & ND & 0.09 \\
\hline 2,4-Dimethyl-1-decene & 15.93 & 1042 & ND & ND & ND & ND & 0.04 \\
\hline 4-Ethyl-1,2-dimethyl benzene & 16.00 & 1044 & ND & 0.13 & ND & ND & ND \\
\hline Limonene & 16.15 & 1048 & 54.66 & 58.18 & 137.24 & 60.92 & 12.56 \\
\hline 2,6,7-Trimethyl decane & 16.85 & 1066 & ND & 0.17 & ND & ND & ND \\
\hline 2,6-dimethyl octane & 16.88 & 1067 & ND & ND & ND & 0.35 & 0.29 \\
\hline 1-ethenyloxy octadecane & 16.95 & 1069 & ND & 0.14 & ND & ND & ND \\
\hline 2,4-dimethyl heptane & 16.97 & 1069 & ND & ND & ND & 0.12 & 0.35 \\
\hline 2,4-Dimethyl hexane & 16.97 & 1069 & ND & ND & ND & ND & 0.08 \\
\hline$\beta$-Phellandrene & 17.06 & 1072 & ND & ND & 0.18 & ND & ND \\
\hline 1-Phellandrene & 17.07 & 1072 & ND & ND & ND & 0.16 & ND \\
\hline$\gamma$-Terpinene & 17.07 & 1072 & 0.14 & 0.17 & ND & ND & ND \\
\hline 3,5-Dimethyl undecane & 17.13 & 1073 & ND & 0.24 & ND & 0.24 & 0.13 \\
\hline 2-Methyl decane & 17.16 & 1073 & ND & ND & ND & ND & 0.15 \\
\hline 2,8-Dimethyl undecane & 17.52 & 1083 & ND & 0.57 & 0.38 & ND & ND \\
\hline 11-1-Ethylpropyl heneicosane & 17.54 & 1083 & ND & ND & ND & 0.42 & ND \\
\hline 3,7-Dimethyl decane & 17.54 & 1084 & ND & ND & ND & ND & 0.27 \\
\hline$\alpha$-Terpinolene & 17.97 & 1094 & ND & 0.78 & 1.02 & 0.67 & ND \\
\hline$\alpha$-Terpinene & 17.98 & 1095 & 0.63 & ND & 0.88 & ND & ND \\
\hline Undecane & 18.23 & 1100 & 0.37 & ND & ND & ND & 0.35 \\
\hline 5-(1-Methyl propyl)-Nonane & 18.72 & 1118 & ND & ND & 0.18 & ND & ND \\
\hline Dodecane & 18.74 & 1200 & ND & ND & ND & ND & 0.14 \\
\hline $1,1^{\prime}$-Oxybis decane & 18.83 & 1122 & ND & 0.15 & 0.14 & 0.06 & ND \\
\hline Dodecyloxy methyl oxirane & 18.94 & 1126 & ND & 0.27 & ND & ND & ND \\
\hline 3-Methyl tridecane & 18.96 & 1127 & 0.20 & ND & ND & ND & ND \\
\hline 2,3,6,7-Tetramethyl octane & 19.03 & 1129 & ND & 0.16 & ND & ND & ND \\
\hline 1-Fluoro dodecane & 19.04 & 1130 & ND & ND & ND & ND & 0.12 \\
\hline 3,7-Dimethyl nonane & 19.04 & 1130 & 0.14 & ND & ND & 0.15 & ND \\
\hline 3-Ethyl-3-methyl heptane & 19.20 & 1135 & ND & ND & 0.09 & ND & ND \\
\hline 1,1,1,2-Tetrafluoro-2-tridecene & 19.21 & 1136 & ND & ND & ND & ND & 0.12 \\
\hline 4-Methyl undecane & 19.96 & 1162 & ND & 0.37 & ND & 0.34 & ND \\
\hline 3-Methyl decane & 19.97 & 1162 & ND & ND & 0.32 & 0.18 & ND \\
\hline 1-Chloro hexadecane & 19.97 & 1162 & ND & ND & ND & ND & 0.17 \\
\hline 2,6,10-Trimethyl dodecane & 19.97 & 1162 & 0.28 & ND & ND & ND & ND \\
\hline 2-Methyl undecane & 20.10 & 1166 & 0.16 & ND & ND & ND & ND \\
\hline 3-Ethyl octane & 20.14 & 1168 & ND & 0.53 & ND & ND & ND \\
\hline $2,6,10,14$-Tetramethyl hexadecane & 20.15 & 1168 & ND & ND & 0.25 & ND & ND \\
\hline 2,6,11-Trimethyl dodecane & 20.16 & 1168 & 0.25 & ND & 0.24 & ND & ND \\
\hline 3,6-Dimethyl undecane & 20.16 & 1168 & ND & ND & ND & ND & 0.19 \\
\hline 3,5,24-Trimethyl tetracontane & 20.28 & 1172 & ND & ND & ND & 0.53 & ND \\
\hline 1-Methoxymethoxy dodecane & 20.65 & 1185 & 0.17 & ND & ND & ND & ND \\
\hline $1,1,4,4,7,7,-$-Hexamethyl cyclononane & 20.73 & 1187 & 0.13 & ND & ND & ND & ND \\
\hline 2,3,5,8-Tetramethyl decane & 20.74 & 1187 & ND & ND & ND & 0.19 & ND \\
\hline Azulene & 20.86 & 1192 & 1.41 & 1.80 & 1.45 & 1.33 & ND \\
\hline Naphthalene & 20.87 & 1192 & ND & ND & ND & ND & 0.84 \\
\hline Camphene & 21.02 & 1197 & ND & 0.53 & 0.17 & 0.10 & ND \\
\hline 1-Methyl-4-1-methyl ethylidene cyclohexene & 21.03 & 1197 & ND & ND & ND & 0.62 & ND \\
\hline Dodecane & 21.12 & 1200 & 1.97 & 2.41 & 2.37 & 2.44 & 1.79 \\
\hline 7-Butyl bicyclo-4,1,0-heptane & 21.26 & 1205 & ND & ND & ND & 0.25 & ND \\
\hline Pulegone & 21.35 & 1209 & ND & 0.62 & ND & ND & ND \\
\hline
\end{tabular}


Table 1. Cont.

\begin{tabular}{|c|c|c|c|c|c|c|c|}
\hline \multirow{3}{*}{ Compounds ${ }^{1)}$} & \multirow{3}{*}{$\begin{array}{l}\text { Retention Time } \\
\text { (min) }\end{array}$} & \multirow{3}{*}{$\begin{array}{l}\text { Retention } \\
\text { Index }\end{array}$} & \multicolumn{5}{|c|}{ Roasting Time (min) } \\
\hline & & & 0 & 2 & 4 & 6 & 8 \\
\hline & & & \multicolumn{5}{|c|}{ Relative Concentration $(\mu \mathrm{g} / 100 \mathrm{~g})$} \\
\hline Decahydro naphthoxirene & 21.36 & 1209 & 0.40 & ND & ND & ND & ND \\
\hline 2,5-Dimethyl undecane & 21.49 & 1214 & ND & 0.47 & ND & ND & ND \\
\hline 2,6-Dimethyl undecane & 21.51 & 1215 & 0.37 & ND & 0.39 & 0.42 & 0.15 \\
\hline 4,6-Dimethyl undecane & 21.51 & 1215 & ND & ND & ND & ND & 0.27 \\
\hline cis-Ocimene & 21.81 & 1226 & ND & 0.94 & ND & ND & ND \\
\hline 1,3-Dimethyl butyl cyclohexane & 22.25 & 1242 & ND & ND & ND & ND & 0.16 \\
\hline Methoxy methoxy cyclooctane & 22.56 & 1254 & ND & ND & ND & 0.28 & ND \\
\hline 2-2-Tetrafuryl methyl tetrahy dropyran & 22.73 & 1260 & ND & 0.43 & ND & ND & ND \\
\hline 4,4-Dipropylheptane & 22.74 & 1260 & 0.30 & ND & ND & ND & ND \\
\hline 2,3,6-Trimethyl decane & 22.86 & 1265 & ND & 0.60 & ND & ND & ND \\
\hline 2,3-Dimethyl undecane & 22.87 & 1265 & 0.49 & ND & ND & ND & ND \\
\hline 2,3,5-Trimethyl decane & 22.87 & 1265 & ND & ND & 0.44 & ND & ND \\
\hline 3-Methyl undecane & 22.87 & 1265 & ND & ND & ND & 0.51 & ND \\
\hline 3-Methyl dodecane & 23.07 & 1272 & ND & ND & 0.32 & ND & ND \\
\hline 2,6-Dimethyl heptadecane & 23.11 & 1273 & 0.73 & ND & ND & ND & 0.23 \\
\hline 3-Methyl nonane & 23.11 & 1274 & ND & ND & ND & 0.67 & ND \\
\hline 2,5,6-Trimethyl-1,3,6-heptatriene & 23.25 & 1279 & 1.78 & ND & ND & ND & ND \\
\hline Tricyclodecane & 23.26 & 1279 & ND & 3.46 & ND & ND & ND \\
\hline Tridecane & 23.83 & 1300 & 4.50 & 5.36 & 5.09 & 5.15 & 3.33 \\
\hline 2-Methyl-1,3-cyclononadiene & 24.81 & 1338 & ND & 0.52 & ND & ND & ND \\
\hline 6-Isopropylidene-1-methyl Bicyclo-3,1,0-hexane & 24.82 & 1339 & ND & ND & 0.81 & ND & ND \\
\hline 4,4-Dipropyl heptane & 25.21 & 1354 & ND & 0.38 & ND & ND & 0.09 \\
\hline 5-Methyl tetradecane & 25.21 & 1355 & 0.28 & ND & ND & ND & ND \\
\hline 2,7-Dimethyl undecane & 25.22 & 1355 & ND & ND & ND & ND & 0.19 \\
\hline 3-Methyl tridecane & 25.64 & 1371 & ND & 0.58 & ND & ND & ND \\
\hline$\alpha$-Cubebene & 26.01 & 1386 & 0.73 & 1.13 & ND & 0.98 & ND \\
\hline Copaene & 26.01 & 1386 & ND & ND & 1.12 & ND & 0.41 \\
\hline Methyl cyclooctane & 26.19 & 1392 & 0.27 & ND & ND & ND & ND \\
\hline$\beta$-Bourbonene & 26.27 & 1395 & ND & ND & 0.56 & 0.35 & ND \\
\hline Tetradecane & 26.39 & 1400 & 2.81 & 3.12 & 3.15 & 2.90 & 1.84 \\
\hline Decyl oxirane & 26.67 & 1415 & ND & ND & ND & ND & 0.27 \\
\hline$\alpha$-Longipinene & 27.01 & 1433 & ND & ND & ND & 0.36 & ND \\
\hline Caryophyllene & 27.16 & 1441 & ND & 24.84 & 52.34 & 32.33 & 5.49 \\
\hline trans-Caryophyllene & 27.16 & 1441 & 26.04 & ND & ND & ND & ND \\
\hline Sinularene & 27.35 & 1451 & ND & 1.13 & ND & ND & ND \\
\hline Aromadendrene & 27.36 & 1451 & ND & ND & ND & 1.05 & ND \\
\hline 1-Hexyl-1-nitrocyclohexane & 27.63 & 1465 & ND & ND & ND & ND & 0.30 \\
\hline$\alpha$-Humulene & 27.99 & 1483 & 1.97 & ND & ND & ND & 0.45 \\
\hline$\alpha$-Caryophyllene & 28.00 & 1483 & ND & ND & ND & 1.99 & ND \\
\hline Germacrene D & 28.65 & 1514 & 1.36 & 3.78 & 5.15 & 1.73 & ND \\
\hline$\alpha$-Farnesene & 28.76 & 1519 & 5.02 & ND & 1.72 & 0.59 & ND \\
\hline 3,7,11-Trimethyl-1,3,6,10-dodecatetraene & 28.77 & 1519 & ND & ND & ND & 6.88 & ND \\
\hline Bicyclogermacrene & 29.01 & 1530 & ND & ND & ND & 1.35 & ND \\
\hline Dispiro-4,2,4,2-tetradecane & 29.23 & 1539 & ND & ND & ND & 0.35 & ND \\
\hline \multicolumn{8}{|l|}{ Ketons (1) } \\
\hline 5,6-Methylidene-2-norbornen-7-one & 11.71 & 921 & ND & ND & 0.24 & ND & ND \\
\hline \multicolumn{8}{|l|}{ Heterocyclic (3) } \\
\hline 4-Ethyl-2,6-dimethyl pyridine & 29.55 & 1045 & 0.56 & ND & ND & ND & ND \\
\hline 3-Methyl-2,3-dihydro benzofuran & 16.02 & 1553 & ND & ND & ND & 0.09 & ND \\
\hline 4-Ethyl-2,6-dimethyl pyridine & 30.70 & 1601 & ND & 0.60 & ND & ND & ND \\
\hline \multicolumn{8}{|l|}{ Miscellaneous (5) } \\
\hline$\alpha$-Terpinenyl acetate & 21.03 & 1118 & 0.45 & ND & ND & ND & ND \\
\hline Dihexyl sulfide & 18.72 & 1197 & ND & ND & ND & 0.26 & ND \\
\hline O-Decyl hydroxylamine & 22.74 & 1260 & ND & ND & ND & ND & 0.21 \\
\hline Methyl benzoate & 23.39 & 1284 & 88.08 & 112.46 & 203.10 & 122.67 & 21.31 \\
\hline Calarene epoxide & 28.22 & 1494 & ND & 0.27 & ND & ND & ND \\
\hline
\end{tabular}

1) Compounds were tentative identified by GC/MSD library connecting HP5-MS column and their retention indices(RIs). ${ }^{2)} \mathrm{NS}$ corresponds not detected.

\subsubsection{Sensory Description by GC-Olfactometry Installed in GC-MS}

A sniffing test of identified volatile compounds was performed by GC-olfactometry in order to describe the sensory attributes of $P$. frutescens Britton during the roasting process. The result of sniffing test by three trained panelists is shown in Table 2. Interestingly, methyl benzoate described as perilla odor gave the highest olfactory intensity (4) throughout the whole roasting time. This result was 
consistent with our volatile compound results. Although the content of methyl benzoate showed an increase and decrease trend as explained in the previous section, the intensity seems strong enough to be perceived by the panelists. Another major volatile compound identified by GC-MS, limonene, described as minty odor was perceived till $4 \mathrm{~min}$ at the lowest intensity (1). This result was also in agreement with our GC-MS result for limonene which was detected up to $4 \mathrm{~min}$ with relatively lower concentration. Whereas in the GC-MS result, azulene was in a small quantity, the sensory attributes of azulene such as spicy, medicinal herb, and garlic odors were perceived intensely ( 4 at 0 and $2 \mathrm{~min}$, 3 at $6 \mathrm{~min}$ ). A previous study detected 13 volatile compounds in the leaves of $P$. frutescens Britton via a GC-olfactometry sniffing test and the most intensely perceived compounds were perilla ketone, (Z)-3-hexenal (green), and egoma ketone [24]. In the present study, $\alpha$-terpinene and $\gamma$-terpinene which elicit bitter odors were perceived with strong intensities at 0,4 and $3 \mathrm{~min}$, respectively, but they were not perceived at all in the roasted samples. As the bitter odor in fresh vegetables is a major cause of deterring consumers from purchase, elimination of the bitter odors through roasting may act positively in increasing perilla consumption.

Table 2. Sensory description and odor intensity of P. frutescens Britton var. acuta Kudo during the roasting using GC-olfactometry.

\begin{tabular}{|c|c|c|c|c|c|c|}
\hline \multirow{3}{*}{ Major Volatile Compounds ${ }^{1)}$} & \multirow{3}{*}{ Odor Description } & \multicolumn{5}{|c|}{ Odor Intensity } \\
\hline & & \multicolumn{5}{|c|}{ Roasting Time (min) } \\
\hline & & 0 & 2 & 4 & 6 & 8 \\
\hline Limonene & Mint & 1 & 1 & 1 & - & - \\
\hline$\alpha$-Terpinene & Bitter & 4 & - & - & - & - \\
\hline Linalool & Sweet & 1 & - & - & 2 & 1 \\
\hline Azulene & Spicy, Medicinal herb, Garlic & 4 & 4 & - & 3 & - \\
\hline 2,6-Dimethylundecane & Oil & 2 & - & - & 2 & - \\
\hline Methyl benzoate & Perilla & 4 & 4 & 4 & 4 & 4 \\
\hline$\gamma$-Terpinene & Bitter & 3 & - & - & - & - \\
\hline 3,7-Dimethyl-1,6-octadien-3-ol & Sweet & 2 & - & - & - & - \\
\hline 2,5-Dimethylundecane & Oil & - & 3 & - & - & - \\
\hline$\beta$-Phellandrene & Spicy, Grass & - & - & 2 & 2 & - \\
\hline$\alpha$-Terpinolene & Spicy, Green onion & - & 3 & 1 & 1 & - \\
\hline$\alpha$-Pinene & Spicy, Pepper & - & - & - & - & 2 \\
\hline 4,4-Dipropylheptane & Roasted & - & - & - & - & 1 \\
\hline
\end{tabular}

1) Compounds were tentative identified by GC/MSD library connecting HP5-MS column and their retention indices(RIs).

\subsection{Constituent and Free Amino Acids Analyses and E-Tongue Analysis}

\subsubsection{Constituent Amino Acids Analysis}

The contents of constituent amino acids in P. frutescens Britton during the roasting were measured using an acid hydrolysis method and the results are shown in Table 3.

Glutamic acid was the most abundant amino acid, followed by aspartic acid, alanine, glycine, leucine, and phenylalanine at $0 \mathrm{~min}$. Overall, the contents of these amino acids showed various patterns without substantial changes. The contents of glutamic acid, aspartic acid, and leucine increased from $14.68 \pm 0.46,12.45 \pm 0.52$, and $8.01 \pm 0.08$ at $0 \mathrm{~min}$ to $15.30 \pm 0.38,12.65 \pm 0.32$, and $8.15 \pm 0.11$ at $8 \mathrm{~min}$, respectively. Glutamic acid alone elicits a sour taste but when it reacts with sodium, it becomes a good flavor enhancer, known as umami taste [26-28]. Aspartic acid and leucine are known to have sour and bitter tastes, respectively [27]. The contents of alanine and glycine, on the other hand, decreased from $8.72 \pm 0.22$ and $8.03 \pm 0.21$ at $0 \mathrm{~min}$ to $8.64 \pm 0.21$ and $7.60 \pm 0.19$ at $8 \mathrm{~min}$, respectively. Both alanine and glycine contribute to sweet taste [27]. Phenylalanine, another compound eliciting bitter taste like leucine [27], showed a slight increase upon roasting from $7.47 \pm 0.96$ at $0 \mathrm{~min}$ to $8.10 \pm 0.73$ at $8 \mathrm{~min}$. Based on the result of this study, P. frutescens Britton is mainly composed of constituent amino acids 
that have umami, sweet, and bitter tastes and these are typical constituent amino acids and relevant tastes found in medicinal herbs such as Cynanchi wilfordii Radix [26].

Table 3. Constituent amino acids in P. frutescens Britton var. acuta Kudo during the roasting.

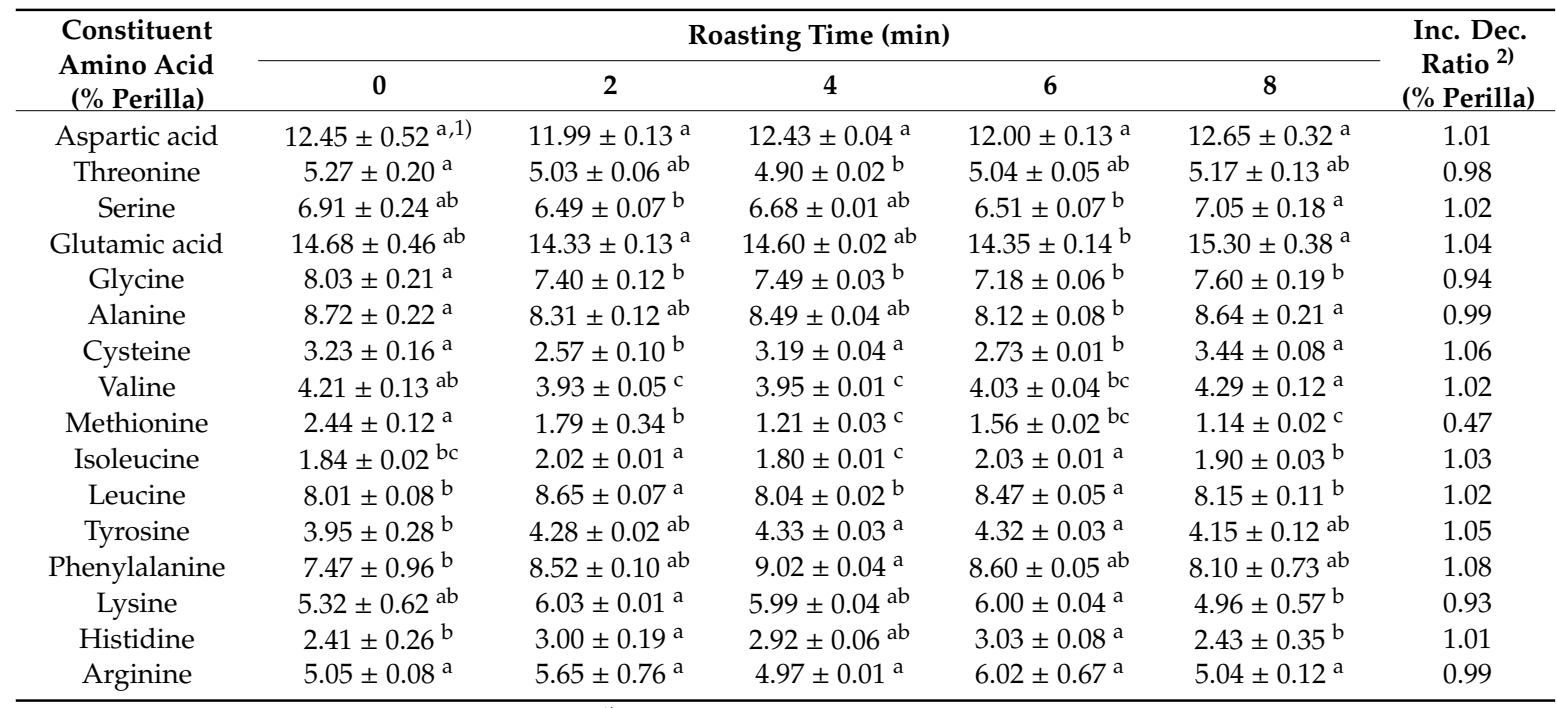

Data represent the mean $\pm \mathrm{SD}$ in triplicate; $\left.{ }^{1}\right)$ Means with different letters $(\mathrm{a}-\mathrm{e})$ within a row are significantly different by Tukey's multiple range test $(p<0.05) ;{ }^{2}$ Increase and decrease ratio was calculated based on amino acid contents at 0 and $8 \mathrm{~min}$. The baseline ratio is 1.00 at $0 \mathrm{~min}$.

\subsubsection{Free Amino Acids Analysis}

The contents of free amino acids in P. frutescens Britton during the roasting were measured by an acid hydrolysis method and the results are shown in Table 4. Alanine was the most prevalent, followed by valine, hydroxylysine, and $\gamma$-aminobutyric acid (GABA). The contents of alanine and GABA exhibited a significant decrease during the roasting from $37.33 \pm 2.79$ and $13.61 \pm 0.01$ at 0 min to $22.73 \pm 1.60$ and $8.96 \pm 0.47$ at $8 \mathrm{~min}$, respectively. Alanine induces sweet taste as previously mentioned [27] and the decreased alanine content with the roasting showed a similar pattern with that of constituent amino acids. GABA is an amino acid inhibitory neurotransmitter that regulates physiological functions and muscle movement in mammals, and a metabolite that controls stress and metabolic pathways in plants $[29,30]$. The contents of valine and hydroxylysine, on the contrary, were increased from $20.24 \pm 0.92$ and $18.13 \pm 0.28$ at $0 \mathrm{~min}$ to $28.59 \pm 0.36$ and $30.73 \pm 1.11$ at $8 \mathrm{~min}$, respectively. Valine elicits bitter taste and acts as a synergistic factor that enhances umami taste [27]. Hydroxylysine induces sweet and bitter tastes [27]. Based on this result, P. frutescens Britton mainly consisted of free amino acids that induce sweet and bitter tastes.

Table 4. Free amino acids in P. frutescens Britton var. acuta Kudo during the roasting.

\begin{tabular}{|c|c|c|c|c|c|c|}
\hline \multirow{2}{*}{$\begin{array}{c}\text { Free Amino } \\
\text { Acid ( } \% \text { Perilla) }\end{array}$} & \multicolumn{5}{|c|}{ Roasting Time (min) } & \multirow{2}{*}{$\begin{array}{l}\text { Inc. Dec. } \\
\text { Ratio }^{2)} \\
\text { (\% Perilla) }\end{array}$} \\
\hline & 0 & 2 & 4 & 6 & 8 & \\
\hline Serine & $1.76 \pm 0.17^{b, 1)}$ & $1.79 \pm 0.14^{b}$ & $2.55 \pm 0.09^{a}$ & $2.00 \pm 0.18^{b}$ & $\mathrm{ND}^{\mathrm{c}}$ & 0 \\
\hline Glycine & $7.42 \pm 0.59^{a}$ & $7.82 \pm 0.30^{a}$ & $8.46 \pm 0.24^{\mathrm{a}}$ & $8.11 \pm 0.76^{\mathrm{a}}$ & $8.97 \pm 1.03^{\mathrm{a}}$ & 1.07 \\
\hline Alanine & $37.33 \pm 2.79^{a}$ & $29.90 \pm 5.99 a, b$ & $28.96 \pm 0.66^{b}$ & $26.98 \pm 1.66^{b}$ & $22.73 \pm 1.60^{b}$ & 0.54 \\
\hline Valine & $20.24 \pm 0.92^{b}$ & $22.76 \pm 2.53^{a, b}$ & $21.79 \pm 0.55^{b}$ & $24.54 \pm 1.51^{a b}$ & $28.59 \pm 0.36^{b}$ & 1.25 \\
\hline Isoleucine & $1.51 \pm 0.06$ & $\mathrm{ND}^{3)}$ & ND & ND & ND & 0 \\
\hline GABA & $13.61 \pm 0.01^{\mathrm{a}, \mathrm{b}}$ & $15.00 \pm 0.11^{\mathrm{a}}$ & $13.86 \pm 0.15^{b}$ & $12.68 \pm 0.17^{c}$ & $8.96 \pm 0.47^{\mathrm{d}}$ & 0.58 \\
\hline Hydroxylysine & $18.13 \pm 0.28^{c}$ & $22.72 \pm 2.19 b c$ & $24.38 \pm 0.35^{b}$ & $25.67 \pm 0.46^{a b}$ & $30.73 \pm 1.11^{a}$ & 1.50 \\
\hline
\end{tabular}

Data represent the mean \pm SD in triplicate; ${ }^{1)}$ Means with different letters $(\mathrm{a}-\mathrm{d})$ within a row are significantly different by Tukey's multiple range test $\left.(p<0.05) ;{ }^{2}\right)$ Increase and decrease ratio was calculated based on amino acid contents at 0 and $8 \mathrm{~min}$. The baseline ratio is 1.00 at $0 \mathrm{~min} .{ }^{3)} \mathrm{NS}$ corresponds not detected. 


\subsubsection{E-Tongue Analysis}

E-tongue analysis was performed to investigate chemical measures associated with the sensory characteristics of $P$. frutescens Britton during the roasting process. The e-tongue analysis result is shown in Figure 1. The relative taste comparison of P. frutescens Britton during the roasting showed that umami and bitterness increased whereas sourness and saltiness decreased. Sweetness remained unchanged. These results can be explained in relation to the constituent and free amino acids compositions explained in the previous section of this study. Increase of umami taste may be associated with the increase of glutamic acid and that of bitterness would be related to the increase of leucine, phenylalanine, and valine as shown in Tables 3 and 4. Although the amino acids eliciting sweet tastes including alanine and glycine increased, sweetness analyzed by e-tongue did not show a marked change over time. In case of sourness, aspartic acid inducing sour taste increased but corresponding sourness by e-tongue decreased. Such a discrepancy is probably because amino acids are not the sole factors of taste development but many other components including sugars, fatty acids, and volatile compounds participate complexely in taste development [27]. Recently, e-tongues have widely utilized to objectively measure tastes in many studies, such as investigation of the taste properties of fermented soybeans with mycelia of Tricholoma matsutake and Bacillus sp. [28], analysis of chemical compounds that may affect sensory properties of different parts of Wasabi koreana Nakai [30], discrimination of geographical origins of red ginseng [31], and investigation of the sensory properties of commercial seasonings [32].

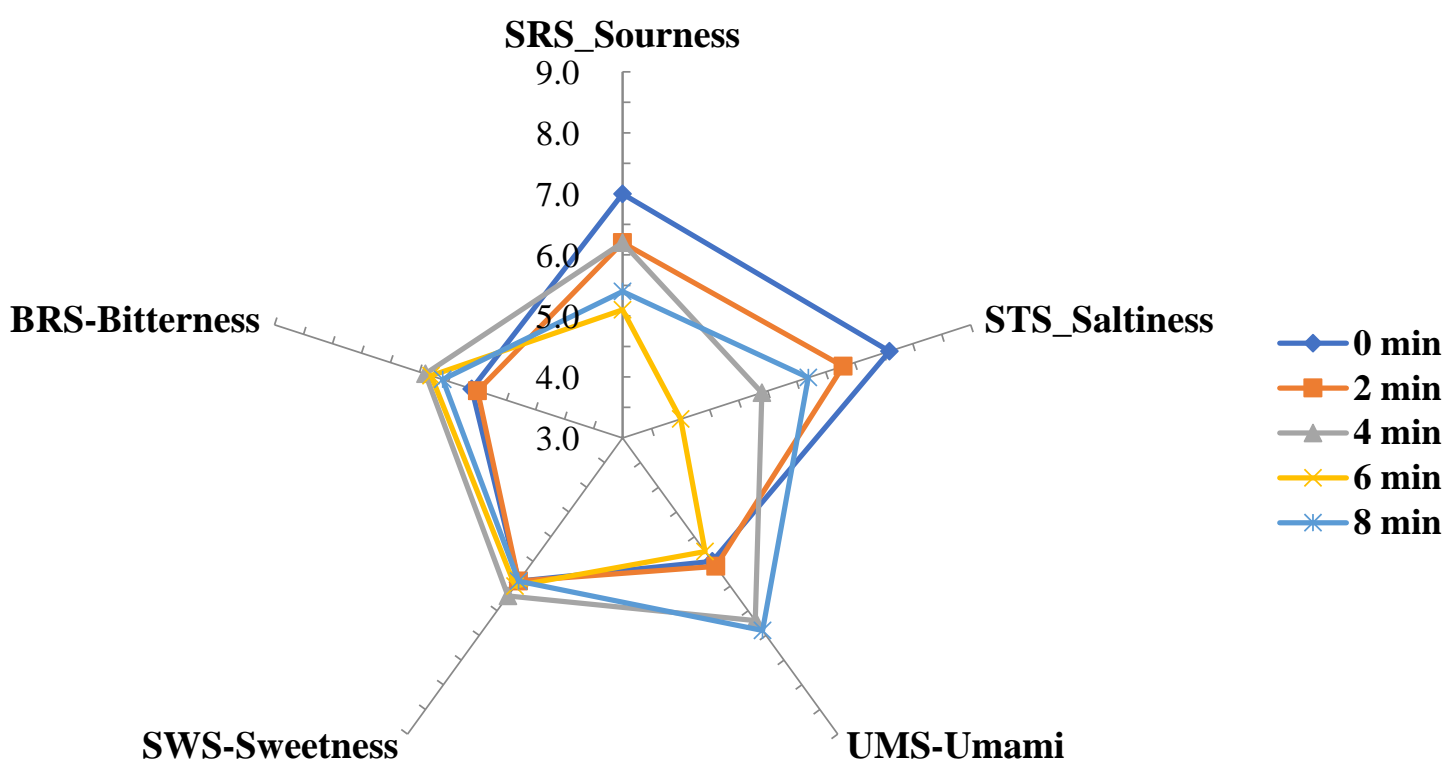

Figure 1. Chemical measures associated with sensory attributes of P. frutescens Britton var. acuta Kudo during the roasting using E-tongue.

\subsection{Chemical Characteristics}

\subsubsection{Total Phenolic Content (TPC)}

Total phenolic content in P. frutescens Britton was determined by the Folin-Ciocalteu's method and the results are shown in Table 5. Total phenolic content is an important indicator of antioxidant capacity [30]. The highest total phenolic content appeared at $4 \mathrm{~min}$ and $6 \mathrm{~min}(0.11 \pm 0.01)$. Phenolic compounds are known to be thermally stable and phenolic antioxidants produced by roasting such as reductone would greatly attribute to the increase of total phenolic content $[26,33]$. The increased total phenolic content, however, decreased to $0.04 \pm 0.01$ at $8 \mathrm{~min}$. In the study by Yun et al. [11] examining optimum roasting conditions of $P$. frutescens leaves for a tea, roasting at $160{ }^{\circ} \mathrm{C}$ for 25 min yielded the highest total phenolic content and the roasting beyond these conditions caused a decrease of the content, which is in agreement with the results of this study. It is therefore necessary to perform more 
studies investigating the optimum time and temperature to obtain high total phenolic content. Based on the results of this study, roasting at $150{ }^{\circ} \mathrm{C}$ for $6 \mathrm{~min}$ would be recommended to produce the highest total phenolic contents in P. frutescens Britton.

\subsubsection{Antioxidant Capacity}

Antioxidant capacity was determined by measuring DPPH (1,1-diphenyl-2-picrylhydrazyl) and ABTS (2,2'-azino-bis-3-ethyl benzothiazoline-6-sulphonic acid) radical scavenging activities and the results are shown in Table 5 . The results of both DPPH and ABTS analyses showed a similar pattern. $\mathrm{IC}_{50}$ values decreased with roasting at 2-6 $\mathrm{min}(84-90 \mathrm{mg})$ and (3 mg) in DPPH and ABTS analyses, respectively, indicating that $P$. frutescens Britton had paramount antioxidant capacity at 2-6 min roasting. Similar to the increase of total phenolic content, thermal processing seems to induce the production of antioxidants and an increase of free polyphenols that can act as electron donors [34]. The antioxidant capacity substantially decreased at $8 \mathrm{~min}$, showing an identical pattern with the result of total phenolic content shown in this study. A recent study by Kim et al. [26], investigated the antioxidative properties of roasted Cynanchi wilfordii Radix and found that the sample roasted at $180{ }^{\circ} \mathrm{C}$ for 4 min produced the highest antioxidant capacity with no clear pattern with the increase of temperature and time. Both our study and the one by Kim et al. [26], indicate that roasting at high temperature for a longer time does not necessarily yield higher antioxidant capacity. Further investigation would be required for discovering the optimum roasting conditions of $P$. frutescens Britton in regards to antioxidant capacity.

\subsubsection{Browning Intensity}

Absorbance at $420 \mathrm{~nm}$ was measured to determine browning intensity and the result is shown in Table 5. Browning intensity of $P$. frutescens Britton tended to increase with roasting time. The absorbance showed $0.15 \pm 0.00$ at $0 \mathrm{~min}$ and reached the highest at $6 \mathrm{~min}, 0.33 \pm 0.00$. It is generally accepted that increased brown color at high temperature over time is mainly caused by Maillard browning [25]. After roasting at $6 \mathrm{~min}$, however, the intensity decreased to $0.23 \pm 0.00$. Another study also observed a similar result in that brown color developed by heat treatment in Polygonatum odoratum roots increased up to a certain time point and decreased afterward [35]. Kwon et al., explained that the substrates involved Maillard reaction such as reducing sugars and amino acids are depleted over time, thereby exerting a decrease in brown color development [35]. Considering that browning intensity is a critical determinant that can influence on consumer preference as well as food quality [25], investigation of proper roasting conditions is deemed necessary in respect to browning intensity.

Table 5. Total phenolic content, antioxidant activity, and browning intensity in P. frutescens Britton var. acuta Kudo.

\begin{tabular}{cccccc}
\hline & \multicolumn{5}{c}{ Roasting Time (min) } \\
\cline { 2 - 6 } & $\mathbf{0}$ & $\mathbf{2}$ & $\mathbf{4}$ & $\mathbf{6}$ & $\mathbf{8}$ \\
\hline $\mathrm{TPC}(\mathrm{mg} / \mathrm{mL})^{1)}$ & $0.04 \pm 0.01^{\mathrm{d}, 2)}$ & $0.11 \pm 0.01^{\mathrm{a}}$ & $0.08 \pm 0.01^{\mathrm{b}}$ & $0.11 \pm 0.01^{\mathrm{a}}$ & $0.04 \pm 0.01^{\mathrm{c}}$ \\
\hline $\mathrm{DPPH}\left(\mathrm{IC}_{50}\right)(\mathrm{mg})$ & 123 & 84 & 86 & 90 & 138 \\
\hline $\mathrm{ABTS}\left(\mathrm{IC} \mathrm{F}_{50}\right)(\mathrm{mg})$ & 4 & 3 & 3 & 3 & 7 \\
\hline $\begin{array}{c}\text { Browning intensity } \\
(420 \mathrm{~nm})\end{array}$ & $0.15 \pm 0.01^{\mathrm{e}}$ & $0.29 \pm 0.01^{\mathrm{b}}$ & $0.25 \pm 0.01^{\mathrm{c}}$ & $0.33 \pm 0.01^{\mathrm{a}}$ & $0.23 \pm 0.01^{\mathrm{d}}$ \\
\hline
\end{tabular}

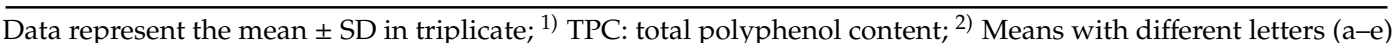
within a row are significantly different by Tukey's multiple range test $(p<0.05)$.

\section{Materials and Methods}

\subsection{Materials and Sample Treatment}

Perilla frutescens Britton var. acuta Kudo leaves cultivated at Sancheong Herb Medicinal Cooperative (Sancheong, Republic of Korea) were purchased. The sample was prepared by the method outlined by 
Kim et al. [36]. The sample was air dried at $60^{\circ} \mathrm{C}$ for moisture removal after which it was subjected to pulverization using a 50-mesh sieve. A sample $(40 \mathrm{~g})$ was roasted at $150{ }^{\circ} \mathrm{C}$ for $0,2,4,6$, and 8 min on a frying pan and an infrared thermometer (Infrared DT-8380, InnoCal Solutions Co., Vernon Hills, IL, USA) was used to measure the temperature. The roasted and pulverized sample was frozen and kept at $-40{ }^{\circ} \mathrm{C}$ until further analyses.

\subsection{Volatile Compound Identification and Sniffing Test Using Gas Chromatography-Olfactometry (GC-Olfactometry)}

\subsubsection{SPME and GC-MS}

Solid-phase microextraction (SPME) fiber coated with polydimethylsiloxane (PDMS) (Supelco, Bellefonte, PA, USA) was used to collect the volatile compounds. Pentadecane (10 $\mu \mathrm{g})$ was dissolved in ethyl ether $(1 \mathrm{~mL})$ and utilized as an internal standard. The sample was heated in a $60^{\circ} \mathrm{C}$ heating block for $20 \mathrm{~min}$ and the volatile compounds were collected for $30 \mathrm{~min}$ in the SPME fiber. After $10 \mathrm{~min}$ desorption, the collected volatile compounds were analyzed by gas chromatography-mass spectrometry (GC-MS, Agilent 7890A and 5975C, Agilent Technologies, Santa Clara, CA, USA). An HP-5MS column $(30 \mathrm{~m} \times 0.25 \mathrm{~mm}$ i.d. $\times 0.25 \mu \mathrm{m}$ film thickness) was used for the analysis. Oven temperature was maintained at $40^{\circ} \mathrm{C}$ for $5 \mathrm{~min}$ and then elevated to $200^{\circ} \mathrm{C}$ at a rate of $5{ }^{\circ} \mathrm{C} / \mathrm{min}$. The injector temperature was set to $220^{\circ} \mathrm{C}$. Helium carrier gas flowed at $1.0 \mathrm{~mL} / \mathrm{min}$ and the split ratio was 1:10. Compounds separated from the total ionization chromatogram (TIC) were identified using the mass spectrum library (NIST 12), ion fragmentation pattern, and a reference [37]. Volatile compounds were determined by semiquantative method based on converting into peak areas of the internal standard. The retention index (RI) was calculated using Equation (1) below:

$$
\mathrm{RI} x=100 n+100((t R x-t R n) /(t R n+1-t R n))
$$

where, RI $x$ is the RI of the unknown compound, $t R x$ is the retention time of the unknown compound, $t R n$ is the retention time of the $n$-alkane, and $t R n+1$ is retention time of the next $n$-alkane. $t R x$ is between $t R n$ and $t R n+1$ ( $n=$ number of carbon atoms).

\subsubsection{Sniffing Test Using GC-Olfactometry Installed in GC-MS}

A sniffing test of volatile compounds separated from GC/MS was carried out using an GC-olfactometry setup with a heated mixing chamber (ODP 3, Gerstel Co., Linthicum, MD, USA) mounted on the spectrometer. The conditions of GC-MS for the sniffing test were the same as described above, Section 3.2.1. Since olfactory recognition differs individually and olfactory sensitivity decreases over time, this study included three trained subjects in the sniffing test [38]. Recognized olfactory intensity was measured by a sensor with four intensity levels. Higher number indicates stronger olfactory intensity.

\subsection{Electronic Tongue and Amino Acids Analyses}

\subsubsection{Constituent Amino Acid Composition}

To determine the contents of constituent amino acids, acid hydrolysis method using hydrochloric acid $(\mathrm{HCl})$ was used. The sample $(0.1 \mathrm{~g})$ and $6 \mathrm{~N} \mathrm{HCl}(3 \mathrm{~mL})$ placed in a $20 \mathrm{~mL}$ flask were stirred for $10 \mathrm{~min}$. The stirred sample was heated in a $110{ }^{\circ} \mathrm{C}$ preheated heating block (Thermo Fisher Scientific Co., Rockford, IL, USA) for $24 \mathrm{~h}$, to induce the acid hydrolysis of proteins to amino acids. A portion $(20 \mu \mathrm{L})$ of the mixture was taken and diluted with commercially available sodium dilution buffer $(1 \mathrm{~mL})$ for amino acid analyzer (Biochrom Ltd., Cambridge, UK). Then, $1 \mathrm{~mL}$ of this solution was filtered with a $0.2 \mu \mathrm{m}$ membrane filter, followed by quantification of constituent amino acids using an automated amino acid analyzer (L-8900, Hitachi HighTech, Tokyo, Japan). 


\subsubsection{Free Amino Acid Composition}

To assess the contents of free amino acids, a sample $(1 \mathrm{~g})$ dissolved in methanol $(20 \mathrm{~mL})$ was stirred for $10 \mathrm{~min}$ and centrifuged at $3000 \mathrm{rpm}$ for $20 \mathrm{~min}$. The supernatant was then dissolved in $25 \mathrm{~mL}$ of the sample dilution buffer and after an addition of sulfosalicylic acid $(20 \mathrm{~mL})$, the sample was incubated at $4{ }^{\circ} \mathrm{C}$ for an hour. The sample was centrifuged at $3000 \mathrm{rpm}$ for $20 \mathrm{~min}$ and then filtered with a $0.2 \mu \mathrm{m}$ membrane filter. The free amino acids were quantified by an automated amino acid analyzer (L-8900, Hitachi High Tech) [26].

\subsubsection{E-tongue Analysis}

An electronic tongue module (E-tongue, ASTREE II, Alpha M.O.S, Toulouse, France) with seven sensors was used to investigate the compounds associated with taste characteristics of $P$. frutescens Britton upon roasting. Two sensors, SPS (spiciness) and GPS (metallic taste) sensors, were set as a reference. SRS (sourness), STS (saltiness), UMS (umami), SWS (sweetness) and BRS (bitterness) sensors represented for 5 basic tastes. The sample, $1 \mathrm{~g}$, was extracted with $100 \mathrm{~mL}$ distilled water at $60^{\circ} \mathrm{C}$ for $10 \mathrm{~min}$ and filtered with Whatman No. 1 filter paper (GE Healthcare, Little Chalfont, UK). The analysis was performed seven times and taste patterns were analyzed by multivariate analysis. The responses from the sensor were converted to scores ranged 1 to 12. Descriptive analysis was given for the resulted taste distribution and the results were shown in a radar plot, which indicates relative comparison among the tastes [39].

\subsection{Chemical Characteristics}

\subsubsection{Total Phenolic Content (TPC)}

Total phenolic content of the sample was measured by Folin-Ciocalteu's method [40]. The sample $(1 \mathrm{mg} / \mathrm{mL})$ was diluted with distilled water. Forty $\mu \mathrm{L}$ of the solution was mixed with distilled water $(200 \mu \mathrm{L})$ and then $2 \mathrm{~N}$ Folin-Ciocalteu's reagent $(200 \mu \mathrm{L}$, Sigma-Aldrich Co., St. Louis, MO, USA) was added and mixed thoroughly for $30 \mathrm{~s}$. Subsequently, 30\% $\mathrm{Na}_{2} \mathrm{CO}_{3}(600 \mu \mathrm{L}$, Sigma-Aldrich Co.) and distilled water $(160 \mu \mathrm{L})$ were added to the solution and incubated at room temperature for $2 \mathrm{~h}$. Total phenolic contents of the sample were determined by absorbance measurement at $750 \mathrm{~nm}$. Gallic acid $(0-500 \mu \mathrm{g} / \mathrm{mL})$ was used as a standard and treated the same procedure as for the sample to quantify total phenolic compounds. Total phenolic content was calculated from the calibration curve.

\subsubsection{Antioxidant Capacity}

To investigate antioxidant capacity in P. frutescens Britton, DPPH (1,1-diphenyl-2-picrylhydrazyl) and ABTS (2,2'-azino-bis-3-ethylbenzothiazoline-6-sulphonic acid) radical scavenging activities were measured. DPPH radical scavenging activity was measured using a slight modification of a method described by Blois [41]. The sample was diluted with distilled water $(0.1,1$, and $10 \mathrm{mg} / \mathrm{mL})$. Next, $0.1 \mathrm{mM}$ DPPH ( $1 \mathrm{~mL}$, dissolved in $99 \%$ ethanol, Sigma-Aldrich Co.) was added to $10 \mu \mathrm{L}$ of diluted sample. The mixture was incubated in the dark at $37^{\circ} \mathrm{C}$ for $30 \mathrm{~min}$. Absorbance was taken at $517 \mathrm{~nm}$ and radical scavenging activity was determined by the equation shown below:

Radical scavenging activity $(\%)=(1-$ absorbance of sample/absorbance of control $) \times 100$

Based on the radical scavenging activity, the $\mathrm{IC}_{50}$ value (the sample concentration where radical scavenging activity reaches $50 \%$ ) was calculated.

ABTS (2,2'-azino-bis-3-ethyl benzo thiazoline-6-sulphonic acid) radical scavenging activity was measured by adapting the method by Van den Berg et al. [42]. $14 \mathrm{mM}$ ABTS solution and $4.9 \mathrm{mM}$ potassium persulfate solution were mixed in a 1:1 ratio and reacted in the dark for $24 \mathrm{~h}$. The mixture was diluted with PBS buffer to make absorbance $0.70 \pm 0.02$ at $734 \mathrm{~nm}$, after which it was used as a working solution. The sample was diluted with distilled water $(0.1,1$, and $10 \mathrm{mg} / \mathrm{mL})$, and $20 \mu \mathrm{L}$ of each diluted 
sample was taken and mixed with $180 \mu \mathrm{L}$ of the working solution. The mixture was subsequently incubated in the dark at $37^{\circ} \mathrm{C}$ for $10 \mathrm{~min}$ and absorbance was measured at $734 \mathrm{~nm}$. Radical scavenging activity was calculated using the same formula above and $\mathrm{IC}_{50}$ value was calculated accordingly.

\subsubsection{Browning Intensity}

To determine browning intensity of $P$. frutescens Britton upon roasting, the sample $(1 \mathrm{~g})$ was extracted with $100 \mathrm{~mL}$ of distilled water at $60^{\circ} \mathrm{C}$ for $10 \mathrm{~min}$. Extracted solution $(200 \mu \mathrm{L})$ was placed in a 96-well plate and absorbance was measured at $420 \mathrm{~nm}$ using a spectrophotometer (Multiskan Go, Thermo-Fisher Scientific Co., Vantaa, Finland). Higher absorbance indicates higher browning intensity.

\section{Conclusions}

For extending the application of $P$. frutescens Britton as a food and food ingredient, this study investigated volatile compounds, sniffing test-assisted sensory properties, constituent and free amino acid compositions, taste description by e-tongue, and chemical characteristics, including TPC, antioxidative capacity, and browning intensity in P. frutescens Britton after roasting at $150{ }^{\circ} \mathrm{C}$ for various time periods. Of 142 volatile compounds identified, methyl benzoate and limonene were the most abundant, and these were also detected as major compounds in the sniffing test-assisted sensory description. Amino acid analyses resulted that among the constituent amino acids, the contents of glutamic acid, aspartic acid, and leucine, which induce umami taste, sour taste, and bitter taste, respectively, increased over the roasting time. Among free amino acids, the contents of valine and hydroxylysine eliciting bitter and bitter and sweet tastes, respectively, increased with roasting. The changes of amino acid composition by roasting were only somewhat matched to the taste description by e-tongue. The changes in sweetness and sourness analyzed by e-tongue did not correspond to the result of amino acid composition. For the chemical properties, TPC, antioxidative capacity, and browning intensity showed an increase pattern with roasting but decreased back after a certain time point $(8 \mathrm{~min})$. The result of this work provides baseline data on volatile and chemical compounds that may affect sensory properties and chemical properties of $P$. frutescens Britton after different roasting times, increasing the feasibility of perilla utilization as a food and food ingredient in both the food industry and the cooking environment.

Author Contributions: "Formal Analysis and Writing-Original Draft Preparation, J.L.; Formal Analysis, Data Curation, and Writing-Original Draft Preparation, D.-S.K.; Data Curation and Writing-Original Draft Preparation, J.C.; Data Curation and Writing-Original Draft Preparation, S.J.H.; Writing-Review \& Editing, J.H.P. and J.K.K.; Supervision, Project Administration, and Funding Acquisition, E.-C.S.". J.L. and D.-S.K. contributed equally to this work as the primary authors.

Funding: This study was funded by the Basic Science Research Program, through the National Research Foundation of Korea (NRF) funded by the Ministry of Education (NRF-2018R1D1A1B07045431) and supported by Agro \& Bio-industry Technology Development Program (Grant No. 314021-03-1-SB030), Ministry of Agriculture, Food and Rural Affairs.

Conflicts of Interest: The authors declare no conflict of interest.

\section{References}

1. He, Y.K.; Yao, Y.Y.; Chang, Y.N. Characterization of anthocyanins in Perilla frutescens var. acuta extract by advanced UPLC-ESI-IT-TOF-MS ${ }^{n}$ method and their anticancer bioactivity. Molecules 2015, 20, 9155-9169. [CrossRef]

2. Kim, Y.; Kim, A.Y.; Jo, A.; Choi, H.; Cho, S.S.; Choi, C. Development of user-friendly method to distinguish subspecies of the Korean medicinal herb Perilla frutescens using multiplex-PCR. Molecules 2017, $22,665$. [CrossRef] [PubMed]

3. Meng, L.; Lozano, Y.F.; Gaydou, E.M.; Li, B. Antioxidant activities of polyphenols extracted from Perilla frutescens varieties. Molecules 2009, 14, 133-140. [CrossRef]

4. Park, J.H.; Yang, C.B. Studies on the removal of phytate from Korean Perilla protein. Korean J. Food Sci. Technol. 1990, 22, 343-349. 
5. Kim, J.; Kang, H.; Choi, H.; Jo, A.; Oh, D.R.; Kim, Y.; Im, S.; Lee, S.G.; Jeong, K.I.; Ryu, G.C.; et al. Aqueous extract of Perilla frutescens var. acuta relaxes the ciliary smooth muscle by increasing NO/cGMP content in vitro and in vivo. Molecules 2018, 23, 1777. [CrossRef] [PubMed]

6. Jun, H.I.; Kim, B.T.; Songm, G.S.; Kim, Y.S. Structural characterization of phenolic antioxidants from purple perilla (Perilla frutescens var. acuta) leaves. Food Chem. 2014, 148, 367-372. [CrossRef]

7. Zhou, X.J.; Yan, L.L.; Yin, P.P.; Shi, L.L.; Zhang, J.H.; Liu, Y.J.; Ma, C. Structural characterization and antioxidant activity evaluation of phenolic compounds from cold-pressed Perilla frutescens var. arguta seed flour. Food Chem. 2014, 164, 150-157. [CrossRef]

8. Jeon, I.H.; Kim, H.S.; Kang, H.J.; Lee, H.S.; Jeong, S.I.; Kim, S.J.; Jang, S.I. Anti-inflammatory and antipruritic effects of luteolin from Perilla (P. frutescens L.) leaves. Molecules 2014, 19, 6941-6951. [CrossRef] [PubMed]

9. Kim, D.H.; Kim, Y.C.; Choi, U.K. Optimization of antibacterial activity of Perilla frutescens var. acuta leaf against staphylococcus aureus using evolutionary operation factorial design technique. Int. J. Mol. Sci. 2011, 12, 2395-2407. [CrossRef]

10. Han, H.S.; Park, J.H.; Choi, H.J.; Sung, T.S.; Woo, H.S.; Choi, J. Optimization of roasted perilla leaf tea using response surface methodology. Appl. Biol. Chem. 2004, 47, 96-106.

11. Yun, U.J.; Yang, S.Y.; Lee, H.S.; Hong, C.O.; Lee, K.W. Optimum roasting conditions for maximizing the quality of tea leached from high functional Perilla frutescens leaves. Korean J. Food Sci. Technol. 2012, 44, 34-40. [CrossRef]

12. Lee, J.M.; Lee, H.R.; Nam, S.M. Optimization for preparation of perilla jangachi according to steaming time and onion contents. Korean J. Food Culture 2002, 17, 653-662.

13. Jang, I.C.; Kang, S.J.; Kim, J.K.; Hyon, J.S.; Kim, M.S.; Moon, Y.H. Effects of addition of perilla leaf powder and carcass grade on the quality and palatability of pork sausage. J. Korean Soc. Food Sci. Nutr. 2003, 32, 350-355.

14. Song, J.; Bi, J.; Chen, Q.; Wu, X.; Lyu, Y.; Meng, X. Assessment of sugar content, fatty acids, free amino acids, and volatile profiles in jujube fruits at different ripening stages. Food Chem. 2019, 270, 344-352. [CrossRef]

15. Centonze, V.; Lippolis, V.; Cervellieri, S.; Damascelli, A.; Casiello, G.; Pascale, M.; Logrieco, A.; Longobardi, F. Discrimination of geographical origin of oranges (Citrus sinensis L. Osbeck) by mass spectrometry-based electronic nose and characterization of volatile compounds. Food Chem. 2019, 277, 25-30. [CrossRef]

16. Castro, A.; Sanchez, A.; Cortez-Delgado, A.; Lopez-Lopez, A.; Montano, A. Effect of Spanish-style processing steps and inoculation with Lactobacillus pentosus starter culture on the volatile composition of cv. Manzanilla green olives. Food Chem. 2019, 271, 543-549. [CrossRef]

17. Guo, X.; Ho, C.; Schwab, W.; Song, C.; Wan, X. Aroma compositions of large-leaf yellow tea and potential effect of theanine on volatile formation in tea. Food Chem. 2019, 280, 73-82. [CrossRef]

18. Kim, J.H.; Oh, S.H.; Park, K.Y. Inhibitory effects of d-Limonene on the mutagenicity and growth of human cancer cells. J. Nat. Sci. 2005, 17, 145-155.

19. Emberger, M.; Lin, J.; Pika, J.; Christ, I.; Eigenbrodt, B. Automated solid-phase microextraction GC-MS/MS method for quantification of volatile limonene oxidation products in encapsulated orange oil. Flav. Fragr. J. 2019, 34, 52-62. [CrossRef]

20. Meng, J.; Liu, Z.; Gou, C.; Rogers, K.; Yu, W.; Zhang, S.; Yuan, Y.; Zhang, L. Geographical origin of Chinese wolfberry (goji) determined by carbon isotope analysis of specific volatile compounds. J. Chromatogr. B. 2019, 1105, 104-112. [CrossRef]

21. Ledesma-Escobar, C.; Proego-Capote, F.; Robles-Olvera, V.; Garcia-Torres, R.; Corcuera, J.; Castro, M. GC-MS study of changes in polar/mid-polar and volatile compounds in Persian lime (Citrus latifolia) during fruit growth. J. Sci. Food Agric. 2018, 99, 1020-1028. [CrossRef]

22. Burdock, G. Fenaroli's Handbook of Flavor Ingredients, 6th ed.; CRC press Taylor \& Francis Group: Boca Raton, FL, USA, 2010; pp. 1090-1216.

23. Ahmed, H.M.; Tavaszi-Sarosi, S. Identification and quantification of essential oil content and composition, total polyphenols and antioxidant capacity of Perilla frutescens (L.) Britt. Food Chem. 2019, 275, 730-738. [CrossRef]

24. Seo, W.H.; Baek, H.H. Characteristic aroma-active compounds of Korean Perilla (Perilla frutescens Britton) leaf. J. Agric. Food Chem. 2009, 57, 11537-11542. [CrossRef]

25. Reineccius, G. Changes in food flavor due to processing. In Flavor Chemistry and Technology, 2nd ed.; Taylor \& Francis Group: Boca Raton, FL, USA, 2006; pp. 103-137. 
26. Kim, D.S.; Kim, H.S.; Hong, S.J.; Cho, J.J.; Shin, E.C. Change in physicochemical and antioxidative properties of Cynanchi wilfordii Radix after a roasting treatment. J. Korean Soc. Food Sci. Nutr. 2018, 47, 363-372. [CrossRef]

27. Kato, H.; Rhue, M.R.; Nishimura, T. Role of free amino acids and peptides in food taste. In Flavor Chemistry: Trends and Developments. J. Am. Chem. Soc. 1989, 388, 158-174.

28. Kim, D.S.; Kim, H.S.; Seo, W.T.; Shin, E.C. Flavor and taste properties of fermented soybeans with mycelia of Tricholoma matsutake and Bacillus sp. J. Korean Soc. Food Sci. Nutr. 2018, 47, 107-115. [CrossRef]

29. Seifikalhor, M.; Aliniaeifard, S.; Hassani, B.; Niknam, V.; Lastochkina, O. Diverse role of $\gamma$-aminobutyric acid in dynamic plant cell responses. Plant Cell Rep. 2019, ePub, 1-21. [CrossRef]

30. Kim, D.S.; Kim, H.S.; Lee, J.; Pan, J.H.; Kim, Y.J.; Kim, J.K.; Woo, S.; Shin, E.C. Wasabi koreana Nakai: A preliminary study on nutrients and chemical compounds that may impact sensory properties. Molecules 2018, 23, 2512. [CrossRef]

31. Dong, H.; Moon, J.Y.; Lee, S.H. Discrimination of geographical origins of raw ginseng using the electronic tongue. Korean J. Food Sci. Technol. 2017, 49, 349-354.

32. Jeon, S.Y.; Kim, J.S.; Kim, G.C.; Choi, S.Y.; Kim, S.B.; Kim, K.M. Analysis of electronic nose and electronic tongue and sensory characteristics of commercial seasonings. Korean J. Food Cook Sci. 2017, 33, 538-550. [CrossRef]

33. Yoon, S.R.; Lee, M.H.; Park, J.H.; Lee, I.S.; Kwon, J.H.; Lee, G.D. Changes in physicochemical compounds with heating treatment of ginseng. J. Korean Soc. Food Sci. Nutr. 2005, 34, 1572-1578.

34. Jang, G.Y.; Kim, H.Y.; Lee, S.H.; Kang, Y.; Hwang, I.G.; Woo, K.S.; Kang, T.S.; Lee, J.; Jeong, H.S. Effects of heat treatment and extraction method on antioxidant activity of several medicinal plants. J. Korean Soc. Food Sci. Nutr. 2012, 47, 914-920. [CrossRef]

35. Kwon, J.H.; Ryu, K.C.; Lee, G.D. Dynamic changes in browning reaction substrates of Polygonatum odoratum roots during roasting. J. Korean Soc. Food Sci. Nutr. 1997, 26, 654-661.

36. Kim, E.K.; Lee, S.J.; Lim, B.O.; Jeon, Y.J.; Song, M.D.; Park, T.K.; Lee, K.H.; Kim, B.; Lee, S.R.; Moon, S.H.; et al. Antioxidative and neuroprotective effects of enzymatic extracts from leaves of Perilla frutescens var.japonica. Food Sci. Biotech. 2008, 17, 279-286.

37. McLafferty, F.W.; Turecek, F. Interpretation of Mass Spectra; University Science Books: Sausalito, CA, USA, 1993; pp. 225-282.

38. Kim, D.S.; Kim, H.S.; Lee, K.T.; Hong, D.L.; Cho, S.R.; Pan, J.H.; Park, Y.B.; Lee, Y.B.; Kim, J.K.; Shin, E.C. Chemical characterization and oxidative stability of medium- and long-chain fatty acid profiles in tree-borne seed oils. J. Anal. Methods Chem. 2018, 2018, 2178684. [CrossRef]

39. Lim, H.J.; Kim, D.S.; Pan, J.H.; Pae, S.B.; Kim, H.S.; Shin, E.C.; Kim, J.K. Characterization of physicochemical and sensory attributes of a novel high-oleic peanut oil cultivar (Arachi hypogaea ssp. Fastigiata L.). Appl. Biol. Chem. 2017, 60, 653-657. [CrossRef]

40. Folin, O.; Denis, W. On phosphotungstic-phosphomolybdic compounds as color reagents. J. Biol. Chem. 1912, 12, 239-243.

41. Blois, M.S. Antioxidant determinations by the use of a stable free radical. Nature 1958, 181, 1199-1200. [CrossRef]

42. Van den Berg, R.; Haenen, G.R.; Van den Berg, H.; Bast, A. Applicability of an improved trolox equivalent antioxidant capacity (TEAC) assay for evaluation of antioxidant capacity measurements of mixtures. Food Chem. 1999, 66, 511-517. [CrossRef]

Sample Availability: Samples of the compounds are not available from the authors. 